Acknowledgments

We thank Dr D. C. L. Savage for advice and encouragement in the preparation of this report, and Dr V. G. Alder, Dr F. Carswell, Dr I. D. Fraser, Dr M. T. Parker and Dr G. L. Scott for assistance with the investigation and management of the patient.

\section{References}

Dale, D.C., Reynolds, H.Y., Pennington, J.E., Elin, R.J., PITTS, T.W. \& GRaW, R.G., Jr (1974) Granulocyte transfusion therapy of experimental Pseudomonas pneumonia. Journal of Clinical Investigation, 54, 664.

De GruChy, G.C. (1964) Clinical Haematology in Medical Practice, 2nd edn, p. 338. Blackwell Scientific Publications, Oxford.

Graw, R.G., Herzig, G., Perry, S \& Henderson, E.S. (1972) Normal granulocyte transfusion therapy. Treatment of septicemia due to Gram-negative bacteria. New England Journal of Medicine, 287, 367.

Hughes, W.T. (1971) Fatal infections in childhood leukemia. American Journal of Diseases of Childhood, 122, 283.

Medical ReSEARCH CounCIL (1971) Hypogammaglobuli- naemia in the United Kingdom. MCR Special Report Series No. 130: London.

Newsome, T.W. \& Eurenius, K. (1973) Suppression of granulocyte and platelet production by Pseudomonas burn wound infection. Surgery, Gynecology and Obstetrics, 136, 375.

Rahal, J.J., Simberkoff, M.S. \& Rubinstein, E. (1974) Intrathecal gentamicin. New England Journal of Medicine, 291, 533.

RoSEN, F.S. \& JANEWAY, C.A. (1966) The gammaglobulins. III. The antibody deficiency syndromes. New England Journal of Medicine, 275, 709.

Sabath, L.D., Casey, J.I., Ruch, P.A., Stumpf, L.L. \& FINLAND, M. (1971) Rapid microassay of gentamicin, kanamycin, neomycin, streptomycin and vancomycin in serum or plasma. Journal of Laboratory and Clinical Medicine, 78, 457.

Speirs, C.F., SelwyN, S. \& Nicholson, D.N. (1963) Hypogammaglobulinaemia presenting as pseudomonas septicaemia. Lancet, ii, 710.

Turgeon, P.L., Laverdiere, M. \& Perron, L. (1975) Successful treatment of Pseudomonas meningitis and septicemia in a leukemic neutropenic adult. American Journal of Clinical Pathology, 63, 135.

\title{
Chronic rhinocerebral phycomycosis in association with diabetes
}

\author{
JULIAN E. FERSTENFELD \\ M.D. \\ HAROLD D. Rose \\ M.D.
}

\author{
Steven H. COHEN \\ M.D.
}

\author{
Michael W. Rytel \\ M.D.
}

Section of Infectious Diseases, Department of Medicine, The Medical College of Wisconsin, Milwaukee County General Hospital, 8700 W. Wisconsin Ave., Milwaukee, Wisconsin 53226, U.S.A.

\section{Summary}

Two patients with rhinocerebral phycomycosis associated with diabetes are presented. The chronic nature of the illness in these two cases is emphasized in contrast to the more fulminant course of most previously reported patients. A high index of suspicion is needed to establish the diagnosis as rapidly as possible. Treatment of the underlying disease combined with amphotericin B therapy and radical surgical excision of all infected tissue is important to establish cure of these patients.

\section{Introduction}

Phycomycosis is a fungal infection caused by organisms belonging to the class Phycomycetes. Clinical infection with these fungi is found in association with pre-existing diseases such as diabetic ketoacidosis, leukaemia and lymphoma, uraemia, cirrhosis, septic abortion, and treatment with steroids and antibiotics. The infection can present clinically in several localized forms such as rhinocerebral, pulmonary or gastrointestinal, or may be seen in a disseminated form (Abramson, Wilson and Arky, 1967; Battock et al., 1968; Best et al., 1971; Gass, 1961; Gregory, Golden and Haymaker, 1943; Helderman, Cooper and Mann, 1974; Hoagland et al., 1961; McBride, Corson and Dammin, 1960; Meyer, Rosen and Armstrong, 1972; Medoff and Kobayashi, 1972; Sander et al., 1971; Straatsma, Zimmermal and Gass, 1962; Touche, Sutherland and Telling, 1963; Wasserman, Shields and Sporn, 1961). The rhinocerebral form is seen most often in association with diabetic ketoacidosis with $75 \%$ of all reported cases having such an association (Battock et al., 1968). Phycomycosis of the rhinocerebral type usually presents as a progressive disease with a fulminant course. Despite present therapy, death often occurs within a few days to several weeks after 
the onset (Abramson et al., 1967; Best et al., 1971; Gass, 1961; Gregory et al., 1943; Helderman et al., 1974; Hoagland et al., 1961; McBride et al., 1960; Meyer et al., 1972; Sander et al., 1971; Straatsma et al., 1961; Touche et al., 1963; Wasserman et al., 1961).

Two cases of documented rhinocerebral phycomycosis in association with diabetic ketoacidosis are presented to draw attention to a more chronic course of the infection. The diagnostic pattern and modalities of therapy of this disease are discussed.

\section{Case 1}

A 61-year-old woman was admitted in diabetic ketoacidosis. Diabetes had been diagnosed 1 year previously during admission for an abdominal aortic aneurysectomy. Adequate control of the diabetes proved difficult, requiring increasing dosages of insulin. During an outpatient clinic visit 1 month before admission, the blood glucose level was $26.5 \mathrm{mmol} / \mathrm{l}$ and a moderate amount of ketones were detected in an undiluted serum specimen.

Physical examination on admission disclosed a lethargic, but responsive woman with blood pressure level of $140 / 80 \mathrm{mmHg}$ supine, and $110 / 80 \mathrm{mmHg}$ sitting; pulse rate was 90 beats/min; respiratory rate $24 / \mathrm{min}$ and deep in character; and the rectal temperature was $96^{\circ} \mathrm{F}$. There were no focal neurological findings. Laboratory studies disclosed the following abnormal values: blood glucose level of $50.8 \mathrm{mmol} / \mathrm{l}$, blood urea nitrogen $0.51 \mathrm{~g} / \mathrm{l}$ arterial blood $\mathrm{pH}$ 6.95, plasma bicarbonate level less than $3 \mathrm{mmol} / 1$ and a moderate amount of ketones were detected in an undiluted serum specimen.

After an initial response of the diabetic ketoacidosis to conventional therapy, the patient demonstrated insulin resistance requiring up to $900 \mathrm{u}$. of regular insulin daily. A moderate degree of ketosis persisted. One week later, the patient became febrile to a level of $102 \cdot 2^{\circ} \mathrm{F}$. No cause of the fever was apparent. Blood and urine cultures were sterile, and sputum culture yielded normal flora. Cerebrospinal fluid showed 16 red blood cells/ $\mu 1,7$ lymphocytes/ $\mu \mathrm{l}$, glucose level of $17 \cdot 1 \mathrm{mmol} / 1$ (blood sugar, $33.3 \mathrm{mmol} / \mathrm{l}$ ), and protein level of $0.7 \mathrm{~g} / 1$. Gram stain and a routine culture of cerebrospinal fluid were negative. The patient was treated with cephalothin without change in the fever, and antibiotics were discontinued after 1 week.

On 10 October, 1973 the patient was noted to have exophthalmos and ophthalmoplegia of the left eye which was thought to be due to cavernous sinus thrombosis, secondary to a generalized hypercoagulable state. One month after admission, ophthalmoplegia and exophthalmos of the left eye persisted and complete loss of vision had occurred. The patient now began to complain of pain around the left eye, and nasal congestion. Examination revealed necrotic material present in the area of the left middle turbinate and sections of a biopsy of this tissue were reported as showing only necrotic tissue. Smear preparation and cultures of this material for fungi were negative. There was radiographic evidence of marked opacification of both maxillary sinuses and the left ethmoid sinus without definite bony destruction. A brain scan was positive and cerebral angiography showed a well circumscribed avascular mass lesion in the left frontal area.

The patient underwent an exploratory craniotomy 7 weeks after admission. A well encapsulated brain abscess was found, but was noted to communicate with the frontal sinus. A Gram stain of material from the abscess revealed what was thought to be Gram-negative rods, although aerobic and anaerobic cultures were negative. Smear preparation and cultures for fungi were negative. Microscopic sections of the necrotic material disclosed subacute and chronic cerebritis consistent with abscess. Therapy with clindamycin and gentamicin was initiated because of the results of the Gram stain.

The patient had an uneventful postoperative course. However, because of continued signs of retro-orbital inflammation, this area was explored 11 days after surgery. Microscopic sections of material obtained during this procedure revealed necrotic adipose tissue, aggregations of inflammatory cells and areas containing prominent eosinophilic branching structures. The morphological appearance of these structures was characteristic of the nonseptate hyphae of Phycomycetes (Fig. 1).

The impression was that the patient had had rhinocerebral phycomycosis since the onset of the fever and ocular findings. A review of the microscopic sections of the material from the brain abscess disclosed similar characteristic fungal elements.

Therapy with amphotericin B was initiated 16 days after operation. Approximately 10 weeks after admission, the patient underwent a left orbital exenteration and left ethmoidectomy. The patient's clinical status continued to improve and the diabetes was now well controlled on diet alone. After only $371 \mathrm{mg}$ (total dose) of amphotericin B had been administered, the drug had to be discontinued because of the side effects, and the patient's refusal to continue the drug. She was discharged 4 months after admission.

The patient has been seen in the outpatient clinic over a 2-year period and has returned to her previous functional capacity. The diabetes has continued to be easily controlled with diet alone, and there is no evidence of recurrence of the phycomycosis.

This case represents rhinocerebral phycomycosis in a setting of diabetic ketoacidosis. In contrast to 


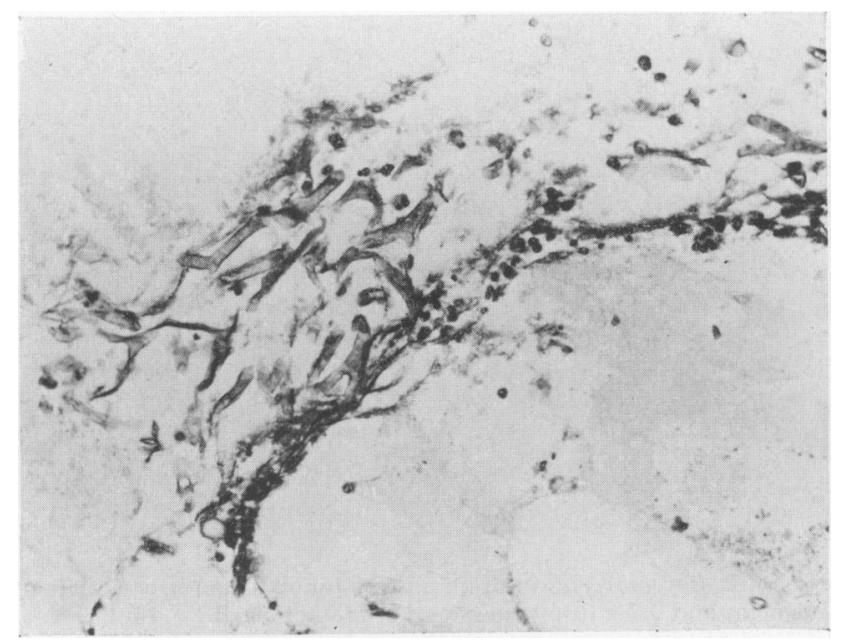

Fig. 1. Patient 1. Large non-septate hyphae of Phycomycetes in retro-orbital tissue from surgical biopsy ( $\times 147)$.

most previously reported cases, this case did not have a fulminant course but rather a more chronic one. The diagnosis was not established until 2 months after admission. Despite this delay of nearly two months before the institution of ampotericin B therapy and surgical excision, the patient's clinical course had been one of slow progressive development of her eye findings and cerebral abscess. The glucose tolerance had been deteriorating for several months before admission and, although speculative, it is feasible that the infection was established some time before her admission and contributed to this deterioration. Her diabetes was then easily managed after specific therapy for the fungal infection.

\section{Case 2}

A 36-year-old American Indian male was admitted to Martin Army Hospital in October 1960, when rhinocerebral phycomycosis was established, he was semi-comatose and in diabetic acidosis. His initial laboratory tests showed a serum acetone test strongly positive in a $1: 2$ dilution, and moderately so in a $1: 4$ dilution; blood glucose of $22.8 \mathrm{mmol} / 1$; blood $\mathrm{CO}_{2}$ was $10.6 \mathrm{mmol} / \mathrm{l}$. After the initial treatment of his ketoacidosis, he improved greatly and became alert and orientated. Chloramphenicol was instituted for a urinary tract infection on 13 October 1960. Four days later the patient complained of a left maxillary 'toothache' and left temporal headache. Over the next few days the course was rapidly downhill with the development of swelling of the entire left side of the face, and protrusion of the left eye. There was X-ray evidence of bilateral maxillary and left ethmoid sinusitis. Biopsy of the sinus area on 22
October revealed the presence of a fungus, later identified as Rhizopus nigrans. Therapy with amphotericin B was initiated intravenously on 24 October. The patient continued to have increasing fever and pulse rate, and lapsed into a deep coma. On 25 October, surgical removal of the left maxilla combined with bilateral ethmosphenoidectomy was performed. Postoperatively, there was thrombosis of the left central retinal vessels and he developed right hemiplegia, which was attributed to thrombosis of the left internal carotid artery.

The patient received a total dose of $2.2 \mathrm{~g}$ of amphotericin B over a 22-day period. Seven months after his admission he was ambulatory with residual right upper extremity paresis and grand mal seizure disorder. The diabetes was controlled with diet alone. This patient was reported at that time by Hoagland et al. (1961) as representing a case of successful treatment with amphotericin $\mathbf{B}$.

The patient was transferred to the Veterans' Administration Hospital, Wood, Winconsin, on 28 August 1961, for plastic and reconstructive surgery of the extensive facial defects. He was in hospital almost continuously until 14 January 1963. The diabetes at this time was well controlled on diet alone, and the seizure disorder was controlled by the administration of $300 \mathrm{mg}$ of diphenylhydantoin daily. The phycomycosis was believed to have been cured.

The patient was readmitted 2 months later on 6 March 1963 for increased right arm weakness and increased frequency of grand mal seizures. The fasting blood sugar was at a level of $5.5 \mathrm{mmol} / \mathrm{l}$, blood urea nitrogen $0.30 \mathrm{~g} / 1$ and the cerebral spinal fluid was reported as normal with negative 


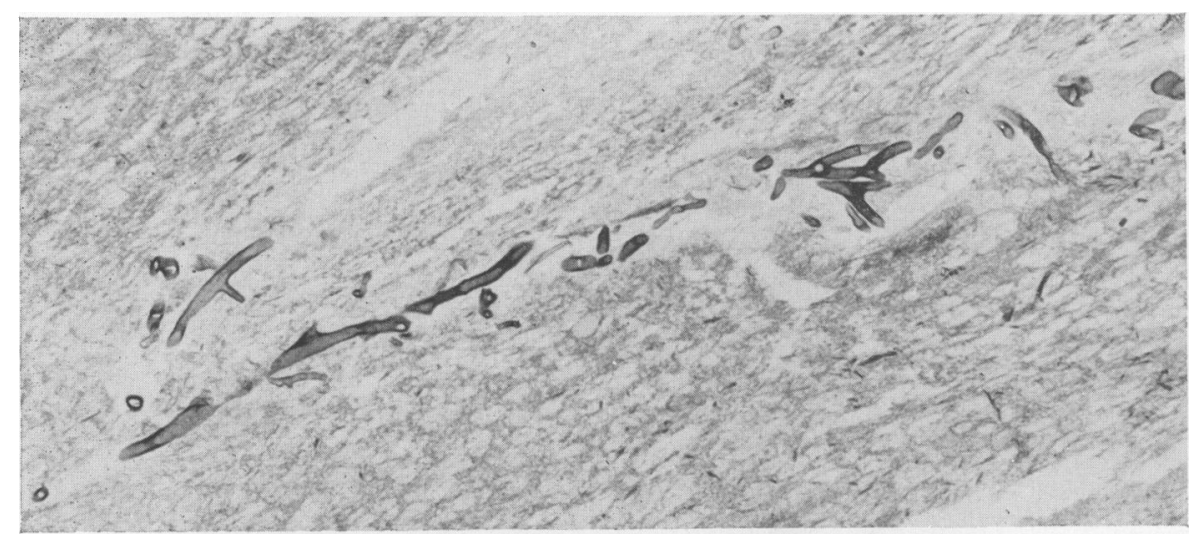

FIG. 2. Patient no. 2. Phycomycetes in brain abscess found at autopsy 3 years after extensive surgical debridement and $2 \cdot 2 \mathrm{~g}$ (total course) of amphotericin $\mathrm{B}(\times 147)$.

cultures for bacteria and fungi. A skull X-ray was normal. An electroencephalogram showed minimal abnormality, suggestive of a focal area of activity in the right occipital area. A neohydrine brain scan revealed an area of increased activity at the base of the brain the midline anterior fossa compatible with a tumour, an abscess or a cyst. Further studies were not performed and the patient was discharged on 4 April 1963.

The final admission was on 7 August 1963, when he presented with vomiting, confusion, lethargy, polyuria, and polydypsia; he had terminated a period of heavy alcohol ingestion 3 days before; no additional information could be obtained. Physical examination disclosed a somnolent, markedly confused man. He was afebrile and there was no evidence of meningeal irritation. There was paresis of the right upper extremity with increased deep tendon reflexes. The white blood cell count was $9.0 \times 10^{9} / 1$ and the differential count showed a shift to the left. Blood glucose level was $5.2 \mathrm{mmol} / \mathrm{l}$, blood urea nitrogen $0.20 \mathrm{~g} / 1$ and serum acetone was not detected. Examination of the cerebrospinal fluid showed 20 white blood cells/ $\mu$ l (19 polymorphonuclear and 1 lymphocyte), protein level of $0.24 \mathrm{~g} / \mathrm{l}$, and glucose $4.4 \mathrm{mmol} / \mathrm{l}$. On the morning following admission the patient developed grand mal seizures which were not controlled by the intravenous administration of diphenylhydantoin or sodium phenobarbital. Seizure activity persisted and the patient died 90 min after the onset.

Significant pathological findings at post-mortem included firmness of the anterior portion of the left frontal lobe with thickened and indurated meninges. Cut sections through this area revealed a granuloma with abscess formation. Unfortunately, the brain was placed in formalin before obtaining material for microbiological study. However, microscopic sec- tions of the brain revealed fungal elements with the morphological appearance of Phycomycetes (Fig. 2).

This case also represents phycomycosis associated with diabetic ketoacidosis. The diagnosis was established within 2 weeks after admission to the hospital, and extensive radical sinus and facial debridement was followed by the administration of a course of $2 \cdot 2 \mathrm{gm}$ of intravenous amphotericin B. No extensive search for an intracranial lesion was made at that time. The patient survived for nearly 3 years after the onset of illness. However, he was eventually readmitted and died within $24 \mathrm{hr}$ of the onset of status epilepticus. The post-mortem finding of a frontal abscess secondary to phycomycosis with evidence of acute changes surrounding this chronic abscess area undoubtedly represents a chronic abscess present since the time of his initial infection.

\section{Discussion}

Phycomycosis was first described by Paltauf in 1885 and was originally referred to as mucormycosis because the infection was found to be caused by members of the family Mucoraceae. Phycomycosis includes infection with Absidia spp., Mucor spp., Rhizopus spp., Mortierella spp., Basidiobolus spp., Entomophthora spp., and Hyphomyces destruens. Most human diseases reported have been caused by the first three genera, while the other genera are most frequently associated with infection in animals (Emmons, Binford and Utz, 1970). These organisms are characterized by broad non-septate hyphae which are 5 to $50 \mu \mathrm{m}$ in width (Abramson et al., 1967). They are found abundantly in nature, producing huge numbers of airborne spores, which produce common bread mould, as well as being found in soil and decaying fruit. Furthermore, their ubiquitous saprophytic nature may be related to their simple metabolism, requiring only sugar and 
simple carbon compounds (McBride et al., 1960). Phycomycetes spp. are frequent laboratory contaminants, growing on blood agar as well as Sabouraud's medium, often covering a Petri dish in a matter of days. For unknown reasons, vigorous efforts to grow these organisms from clinical specimens are frequently unsuccessful.

The clinical course of rhinocerebral phycomycosis in association with diabetic ketoacidosis is remarkably predictable. The usual portal of entry is the upper respiratory passages with the initial site of infection being in the nasal sinuses; occasionally, however, infection may begin in the orbital tissue (Battock et al., 1968). Nasal congestion and local complaints of pain around the eye and over the sinuses may be the patient's first complaints. After the initial locus of infection, lesions appear in the nasal septum, turbinates, nasal mucosa, palate or pharnyx. These are characterized by avascular necrotic tissue as the fungus spreads by direct extension or by vascular invasion and intravascular propagation. The fungus is able to penetrate and grow in the walls of both arteries and veins. Subsequently, thrombosis and necrosis ensue and hyphae may be found within the clot (Touche et al., 1963). Focal extension continues to involve the paranasal sinuses, cribriform plate, extending then to the meninges and ultimately the brain (Best $e t$ al., 1971).

After the initial non-specific complaints, specific symptoms and signs develop. As previously outlined by Smith and Kirchner (1958), they include: (1) dark blood-tinged nasal discharge from the corresponding side of facial pain; (2) periorbital and perinasal swelling which progresses to induration and discoloration as vascular occlusion progresses; (3) ptosis of the eyelid, exophthalmos and ophthalmoplegia of the affected eye; (4) multiple unilateral cranial and systemic palsies; (5) black necrotic turbinates which can be easily mistaken for dried crusted blood. Additionally, there is progressive lethargy, unilateral headache, hemifacial anaesthesia, loss of vision, convulsions, or other evidence of meningoencephalitis (Abramson et al., 1967).

After the infection becomes established, it tends to run a rapid fulminant course in spite of correction of the underlying ketoacidosis. Death can occur from days to weeks after the onset of symptoms, and the diagnosis is frequently made at post-mortem examination (Abramson et al., 1967; Wasserman et al., 1961).

Given the classic progression of findings and clinical setting, the diagnosis should be suspected. $\mathrm{X}$-ray studies of the paranasal sinuses may reveal localized or parasinusitis with or without evidence of bony destruction. Electroencephalogram, radioisotopic brain scan and cerebral angiography should be undertaken to exclude cerebral involvement.

The major differential consideration is cavernous sinus thrombosis. In this disorder, exophthalmos is a late feature and visual loss is rare compared to the early appearance of both in rhinocerebral phycomycosis (Abramson et al., 1967). The diagnosis is confirmed by finding the characteristic large non-septate hyphae in smear preparations or microscopic sections of clinical specimens. Since the organisms may be few in number and scattered in a large mass of necrotic, avascular tissue, a diligent search of tissue specimens may be necessary to disclose the presence of the organism. As previously mentioned, isolation of the organism from appropriate culture media is often difficult.

The two patients presented here demonstrated the classic clinical presentation with the notable exception of a more chronic, rather than fulminant nature of the illness. The first patient exemplified an indolent form, having a clinical course of 4-6 weeks before the diagnosis was established and therapy instituted. Recently, Helderman et al. (1974) reported a patient with a chronic indolent course. The second patient reported here also had the classic clinical setting. The diagnosis was made rapidly and combined surgical and amphotericin B therapy instituted. No extensive evaluation was made for the possibility of central nervous system involvement and the patient died 3 years later during an episode of status epilepticus. The post-mortem examination disclosed a chronic brain abscess caused by $P h y$ comycetes with evidence of more acute changes at the border of the abscess. There was no other evidence of residual infection. This appears to have been a chronic abscess present for 3 years with evidence of continued activity in the periphery of the abscess. To the authors' knowledge, no other similar case has been reported.

There are no definitive studies as to the ideal mode of therapy for rhinocerebral phycomycosis. To date, there are only twenty reported cases of cure of this disease in the literature (Best et al., 1968). The second patient presented in this paper was reported previously by Hoagland et al. (1961) as a successfully treated case. There have been two reported cases of cure before the availability of amphotericin B therapy (Hoagland et al., 1961; Wasserman et al., 1961). These cases were treated with surgical excision of infected tissue, and one patient was also treated with nystatin and potassium iodide. Other reported cures have been with combinations of control of diabetes, amphotericin B and surgical excision. Dosages of amphotericin B employed have ranged from a few hundred milligrams to nearly $3.5 \mathrm{~g}$. Although there has been in vitro evidence of inhibition of the fungus by amphotericin B (Watson 
and Neame, 1960), conclusive clinical evidence of efficacy and guidelines as to optimal total dosage and duration of therapy have not been established.

Several observations can be made from previously reported cases and from the two patients presented here to formulate the most rational approach to therapy of rhinocerebral phycomycosis. First, a high index of suspicion is needed to establish the diagnosis as rapidly as possible. Treatment of the underlying disease, most often diabetic ketoacidosis, is crucial to overall survival. Amphotericin B is the only currently available antifungal agent with any apparent activity against the causative organism which may alter the course of human infection. A course of amphotericin B with a total dose of $2.0 \mathrm{~g}$, as in several other deep mycoses, seems the most reasonable approach. Finally, a radical surgical approach to remove all infected tissue seems imperative. The second patient presented here had inadequate surgical removal of infected tissue, and the infection persisted even after what was considered an adequate course of amphotericin B. A diligent diagnostic search adequately to define the extent of tissue involvement, therefore, is necessary, and radical surgical removal of these tissues may be the most important factor in the permanent cure of patients with this infection.

\section{References}

Abramson, E., Wilson, D. \& ARKy, R.A. (1967) Rhinocerebral phycomycosis in association with diabetic ketoacidosis: report of two cases and a review of clinical and experimental experience with amphotericin B therapy. Annals of Internal Medicine, 66, 735.

Battock, D.J., Grausz, H., Bobrowsky, M. \& Littman, M.L. (1968) Alternate day amphotericin B therapy in the treatment of rhinocerebral phycomycosis (mucormycosis). Annals of Internal Medicine, 68, 122.

Best, M., Obstbuum, S.A., Friedman, B. \& Strobos, R.J.
(1971) Survival in orbital phycomycosis. American Journal of Ophthalmology, 71, 1078.

Emmons, C.W., BinfoRd, C.H. \& Utz, J.P. (1970) Phycomycosis. In: Medical Mycology. Lea \& Febiger, Philadelphia.

Gass, J.D.M. (1961) Acute orbital mucormycosis. Report of two cases. Archives of Ophthalmology, 65, 214.

GREgoRY, J.E., GOLDEN, A. \& HAYMAKER, W. (1943) Mucormycosis of the central nervous system. Bulletin of the Johns Hopkins Hospital, 73, 405.

Helderman, J.H., Cooper, H.S. \& MaNN, J. (1974) Chronic phycomycosis in a controlled diabetic. Annals of Internal Medicine, 80, 419.

Hoagland, R.J., Sube, J., Bishop, R.H. \& Holding, B.F. (1961) Mucormycosis. American Journal of the Medical Sciences, 242, 415.

McBride, R.A., Corson, J.M. \& DAmmin, G.J. (1960) Mucormycosis: two cases of disseminated disease with cultural identification of Rhizopus; review of the literature. American Journal of Medicine, 28, 832.

Meyer, R.D., Rosen, P. \& Armstrong, D. (1972) Phycomycosis complicating leukemia and lymphoma. Annals of Internal Medicine, 77, 871.

Medoff, G. \& Kobayashi, G.S. (1972) Pulmonary mucormycosis. New England Journal of Medicine, 286, 86.

NeAme, P. \& RAYNOR, D. (1960) Mucormycosis, a report on twenty-two cases. Archives of Pathology, 70, 261.

Paltauf, A. (1885) Mycosis mucorina (Ein Beitrag zur Kenntniss der menschlichen Fadenpilzerkrankungen). Virchows Archiv; Abteilung A: Pathologische Anatomie, 102, 543.

Sander, R., Tallman, C.B., Keamy, D.G. \& Irving, W.R. (1971) Successfully treated rhinocerebral phycomycosis in well controlled diabetes. New England Journal of Medicine, $285,1180$.

SMITH, H.W. \& KirChNER, J.A. (1958) Cerebral mucormycosis. Archives of Otolaryngology, 68, 715.

StraAtsma, B.R., Zimmermal, L.E. \& Gass, J.D.M. (1962) Phycomycosis, a clinicopathologic study of fifty-one cases. Laboratory Investigation, 11, 963.

Touche, C.J.L., Sutherland, T.W. \& Telling, M. (1963) Rhinocerebral mucormycosis Lancet, ii, 811.

Wasserman, A.J., Shields, W.S. \& SPORN, I.N. (1961) Cerebral mucormycosis. Southern Medical Journal, 54, 403.

WATSON, K.C. \& NEAME, P.B. (1960) In vitro activity of amphotericin B on strains of Mucoraceae pathogenic to man. Journal of Laboratory and Clinical Medicine, 56, 251. 